\title{
Use of A Hydroalcoholic Extract of Moringa oleifera Leaves for the Green Synthesis of Bismuth Nanoparticles and Evaluation of Their Anti-Microbial and Antioxidant Activities
}

\author{
Prince Edwin Das ${ }^{1}$, Amin F. Majdalawieh ${ }^{2}, * \mathbb{D}$, Imad A. Abu-Yousef ${ }^{2}$, Srinivasan Narasimhan ${ }^{1, *}$ \\ and Palmiro Poltronieri ${ }^{3, * \text { D }}$ \\ 1 Asthagiri Herbal Research Foundation, 162A, Perungudi Industrial Estate, Perungudi, Chennai 600096, \\ India; prince.ahrf@gmail.com \\ 2 Department of Biology, Chemistry and Environmental Sciences, American University of Sharjah, Sharjah, \\ P.O. Box 26666, UAE; iabuyousef@aus.edu \\ 3 Institute of Sciences of Food Productions, CNR-ISPA, 73100 Lecce, Italy \\ * Correspondence: amajdalawieh@aus.edu (A.F.M.); narasimhan_s@yahoo.com (S.N.); \\ palmiro.poltronieri@ispa.cnr.it (P.P.)
}

Received: 20 December 2019; Accepted: 12 February 2020; Published: 15 February 2020

\begin{abstract}
The employment of plant extracts in the synthesis of metal nanoparticles is a very attractive approach in the field of green synthesis. To benefit from the potential synergy between the biological activities of the Moringa oleifera and metallic bismuth, our study aimed to achieve a green synthesis of phytochemical encapsulated bismuth nanoparticles using a hydroalcoholic extract of M. oleifera leaves. The total phenolic content in the M. oleifera leaves extract used was $23.0 \pm 0.3 \mathrm{mg}$ gallic acid equivalent/g of dried M. oleifera leaves powder. The physical properties of the synthesized bismuth nanoparticles were characterized using UV-Vis spectrophotometer, FT-IR spectrometer, TEM, SEM, and XRD. The size of the synthesized bismuth nanoparticles is in the range of 40.4-57.8 nm with amorphous morphology. Using DPPH and phosphomolybdate assays, our findings revealed that the $M$. oleifera leaves extract and the synthesized bismuth nanoparticles possess antioxidant properties. Using resazurin microtiter assay, we also demonstrate that the $M$. oleifera leaves extract and the synthesized bismuth nanoparticles exert potent anti-bacterial activity against Escherichia coli, Klebsiella pneumoniae, Staphylococcus aureus, and Enterococcus faecalis (estimated MIC values for the extract: 500, 250, 250, and $250 \mu \mathrm{g} / \mathrm{mL}$; estimated MIC values for the bismuth nanoparticles: 500, 500, 500, and $250 \mu \mathrm{g} / \mathrm{mL}$, respectively). Similarly, the $M$. oleifera leaves extract and the synthesized bismuth nanoparticles display relatively stronger anti-fungal activity against Aspergillus niger, Aspergillus flavus, Candida albicans, and Candida glabrata (estimated MIC values for the extract: 62.5, 62.5, 125, and $250 \mu \mathrm{g} / \mathrm{mL}$; estimated MIC values for the bismuth nanoparticles: 250, 250, 62.5, and $62.5 \mu \mathrm{g} / \mathrm{mL}$, respectively). Thus, green synthesis of bismuth nanoparticles using M. oleifera leaves extract was successful, showing a positive antioxidant, anti-bacterial, and anti-fungal activity. Therefore, the synthesized bismuth nanoparticles can potentially be employed in the alleviation of symptoms associated with oxidative stress and in the topic treatment of Candida infections.
\end{abstract}

Keywords: Moringa oleifera; bismuth nanoparticles; polyphenolics; anti-bacterial; anti-fungal; antioxidant

\section{Introduction}

Moringa oleifera (family Moringaceae) is among the most studied herbs. It is considered a sacred plant and referred to as the "tree of life" in several cultures. It has been widely cultivated in various 
parts of the world and for many decades because of its potential use in numerous applications in industry, pharmacy, and medicine. Both its leaves and fruits are used in cooking, and they are part of many cuisines worldwide. Moreover, many home remedies and traditional medicinal formulations are prepared using every part of $M$. oleifera [1]. Its leaves are edible and they are of considerable nutritional and therapeutic value due to their rich vitamin and amino acid content [2]. Experimental evidence suggests that the diverse medical applications of $M$. oleifera leaves can be partially attributed to the antioxidant potential of the phenolic compounds found in the leaves [3]. For many years, plant-based compounds and their derivatives have been used in the manufacturing of textiles, fabrics, polymers for food and non-food applications, biomaterials for biofilm formation as well as oral hygiene and dental caries prevention, and foil polymers for food packaging and wrapping [4-9]. The antimicrobial and antioxidant properties of silver and other metallic nanoparticles forced the development of several new nanomaterials, followed by the evaluation of their biological activities [10-15].

Several active compounds (e.g., proteins, flavonoids and carboxylic groups of arabinose and galactose, reducing sugars, aliphatic amines, tannins, aliphatic alkenes of alkaloids, aromatic amines, polysaccharides, sec-alcohols, saponins, and water-soluble heterocyclic components) isolated from plant extracts have been used in the successful synthesis of silver nanoparticles [16]. Individually, many plant extracts and metallic nanoparticles are known to possess significant biological activities both in vitro and in vivo. As such, it is envisioned that the use of plant extracts in the green synthesis of metallic nanoparticles may cause a synergistic effect leading to more robust biological activities. Hence, the use of plant extracts to synthesize metallic nanoparticles may lead to the formation of new nanomaterial with more potent and/or novel biological activities [17]. Indeed, several studies demonstrate the successful synthesis of silver and gold nanoparticles using the leaves' extracts of Erythrina suberosa (Roxb.), Paederia foetida, Acalypha indica, Cassia auriculata, Sorbus aucuparia, and Azadirachta indica, and their antimicrobial activities were assessed and confirmed [18-23]. Along the same line, other studies demonstrated that silver nanoparticles that were synthesized using various plant extracts exert potent antioxidant activity [24-29].

Bismuth nanoparticles with a size of $25 \mathrm{~nm}$ were successfully synthesized by using the laser ablation method, and they can be utilized as high contrast medium for high-resolution imaging in several biological applications [30]. Notably, bismuth nanoparticles synthesized by conventional solvent techniques have a size in the range of 50-103 nm with a very high anti-wear property [31]. Bismuth nanoparticles are also used as catalysts in reduction of nitro compounds to azo compounds [32]. Bismuth nanoparticles, with a size of $40 \mathrm{~nm}$, which were synthesized by using the colloidal-chemical method in water medium, were shown to exert potent anti-microbial activity against several pathogenic microorganisms [33].

Bismuth nanoparticles with better catalytic activity were synthesized by the redox reactions between ammonium bismuth citrate and sodium borohydride in the presence of soluble starch in aqueous phase [34]. Bismuth nanodots were synthesized by the redox reaction between D-glucose and bismuth nitrate, in the presence of polyvinylpyrrolidone in the basic aqueous phase. The reduction of 4-nitrophenol to 4-aminophenol requires $36 \mu \mathrm{g} / \mathrm{mL}$ nano-catalyst for $20 \mathrm{mM}$ of the substrate [35]. A mechano-chemistry pathway was used to prepare nanostructured Ag-Bi alloys under normal conditions and with the minimum amount of solvent. These nanostructured Ag-Bi alloys effectively degraded NO but they were rapidly oxidized [36]. Bismuth nanoparticles-decorated multi-wall carbon nano-tubes were synthesized and modified carbon paste electrodes were fabricated to serve as a novel amperometric sensor for the purpose of gallic acid detection. This sensor estimates gallic acid in cloves and green tea extracts with complete elimination of interferences [37]. Zerovalent bismuth nanoparticles were synthesized by a two-pot synthetic approach based on a combination of cementation process and a wet ball-stirring process [38]. Numerous studies were reported on the synthesis and characterization of bismuth sulfide, bismuth oxide, and spherical bismuth metallic nanoparticles. Various strategies and different capping agents were used to control the morphology, size, and stability of these nanoparticles. In the medical field, bismuth nanoparticles were used as an X-ray contrast 
agent [39]. Under a low X-ray dose, a radiosensitizer comprised of bismuth nanoparticles attached to antibodies was used to specifically and selectively target and kill multidrug resistant bacteria [39].

Herein, we attempted to achieve enhanced biological activities of bismuth nanoparticles via their synthesis using M. oleifera leaves' phytochemical constituents. To this end, we pursued green synthesis of bismuth nanoparticles using a hydroalcoholic extract of $M$. oleifera leaves, followed by their physical characterization using different techniques. We also assessed the antioxidant activity of M. oleifera leaves extract and of synthesized phytochemical encapsulated bismuth nanoparticles, as well as their anti-bacterial and anti-fungal activities against different species of bacteria and fungi. We anticipate that our findings will be significant in the employment of green-synthesized bismuth nanoparticles in several medical applications.

\section{Results and Discussion}

\subsection{Phytochemical Analysis of the M. oleifera Leaves Extract}

The qualitative evaluation of various chemical constituents in the M. oleifera leaves extract was performed using the test methods mentioned in Table 1. The protein content in the M. oleifera leaves extract was estimated to be $0.1 \%$ of the dry leaves powder. The total phenolic content in M. oleifera leaves extract was $23 \%$ of the dry leaves powder. An earlier study demonstrated that alanine, tyrosine, lysine, and threonine are among the major amino acids present in the M. oleifera leaves extract [40]. The concoction of $M$. oleifera leaves extract contains isomers of ceffeoylquinic acid, isomers of feruloylquinic acid, tannins, gallic acid, and several flavonoids like quercetin, kaempferol (Figure S1) and their glycoside derivatives [41]. Using High-performance liquid chromatography (HPLC) analysis, isoquercetin, astragalin, and crypto-chlorogenic acid were identified in the ethanolic extract of $M$. oleifera leaves [42]. The hydroalcoholic extract of M. oleifera leaves (water/ethanol 50:50), contains numerous unexplored macromolecules. Collectively, such findings suggest that the M. oleifera leaves extract could serve as a nutritional supplement and a possible stabilizing agent for the synthesized bismuth nanoparticles.

Table 1. Phytochemical analysis of the M. oleifera leaves extract. The presence of the indicated chemical constituents is indicated with $(+)$.

\begin{tabular}{ccc}
\hline Chemical Constituents & Test Method & M. oleifera Leaves Extract \\
\hline Alkaloids & Dragendroff's test & + \\
Tannins & Ferric chloride & + \\
Flavonoids & Shinoda test & + \\
Steroids & Salkowski reaction & + \\
Saponins & Foam test & + \\
Polyphenols & Puncal-D & + \\
Glycosides & Conc. $\mathrm{H}_{2} \mathrm{SO}_{4}$ and heat & + \\
Carbohydrates & Anthrone test & + \\
Proteins & Ninhydrin test & + \\
Amino acids & Millon's test & \\
\hline
\end{tabular}

From the total phenolic content estimation of the M. oleifera leaves extract before and after the reaction (Table 2), Scheme 1 is proposed. The total phenolic content of $60 \mathrm{mg}$ gallic acid equivalent from $10 \mathrm{~g}$ of dried M. oleifera leaves powder was used in the synthesis of $170 \mathrm{mg}$ of bismuth nanoparticles from $0.04 \mathrm{M}$ of bismuth (III) ion solution. The reducing and binding chemical entities present in the concoction aid in the formation and stabilization of the synthesized bismuth nanoparticles through encapsulation. A color change from light brown to dark brown indicates the successful formation of bismuth nanoparticles. 
Table 2. Determination of total phenolic content before and after the synthesis of bismuth nanoparticles.

\begin{tabular}{cc}
\hline Sample & $\begin{array}{c}\text { Total Phenolic Content } \\
\text { (mg/g of Dried Leaves) }\end{array}$ \\
\hline $\begin{array}{c}\text { M. oleifera leaves extract } \\
\text { (before synthesis) }\end{array}$ & $23.0 \pm 0.3$ \\
\hline $\begin{array}{c}\text { M. oleifera leaves extract } \\
\text { (after synthesis) }\end{array}$ & $17.0 \pm 0.4$ \\
\hline
\end{tabular}

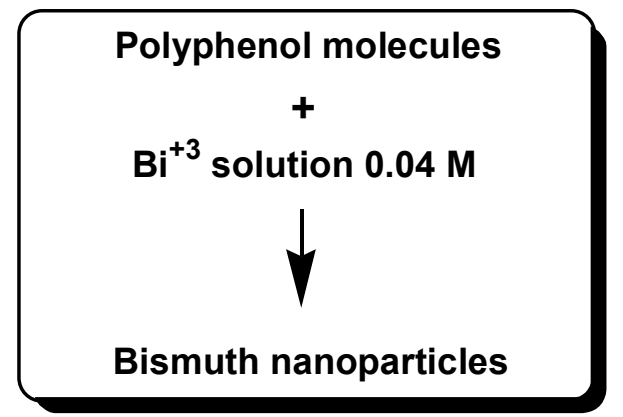

Scheme 1. Schematic representation of bismuth nanoparticles synthesis.

\subsection{Characterization}

\subsubsection{Size and Morphology of the Synthesized Bismuth Nanoparticles}

The high-resolution transmission electron microscopy (HRTEM) image of synthesized bismuth nanoparticles was captured using a JEOL-TEM 2100 plus electron microscope (Figure 1). EDS (energy dispersive X-ray spectroscopy) studies indicate only the presence of elements in the sample (Figure 2).

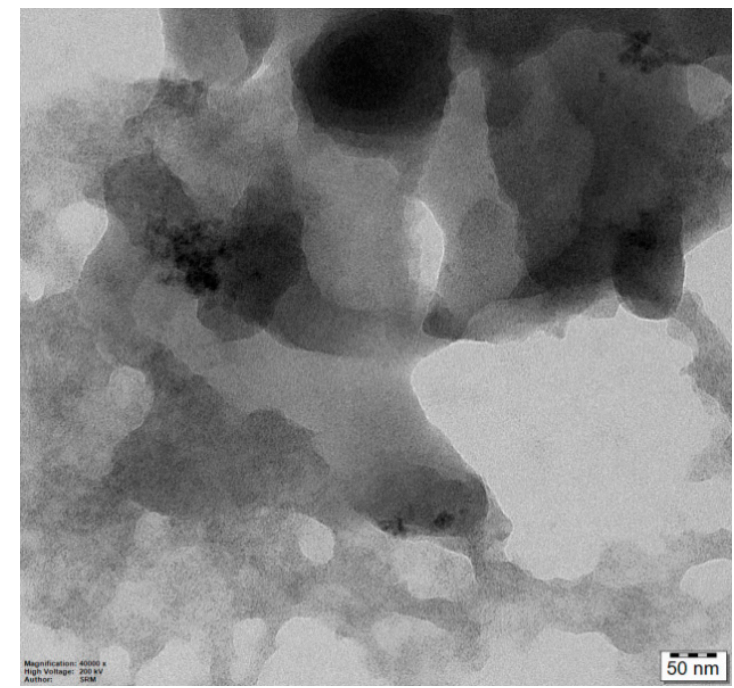

(a)

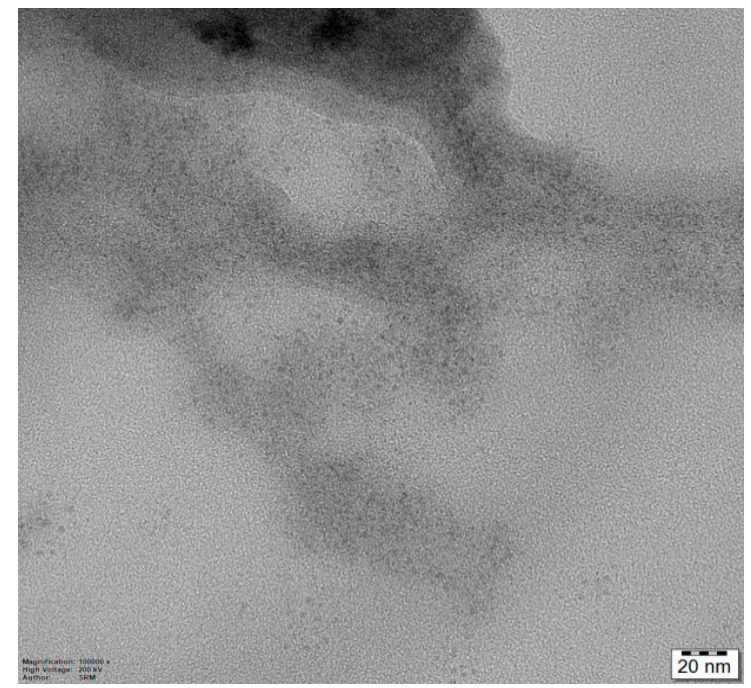

(b)

Figure 1. Cont. 


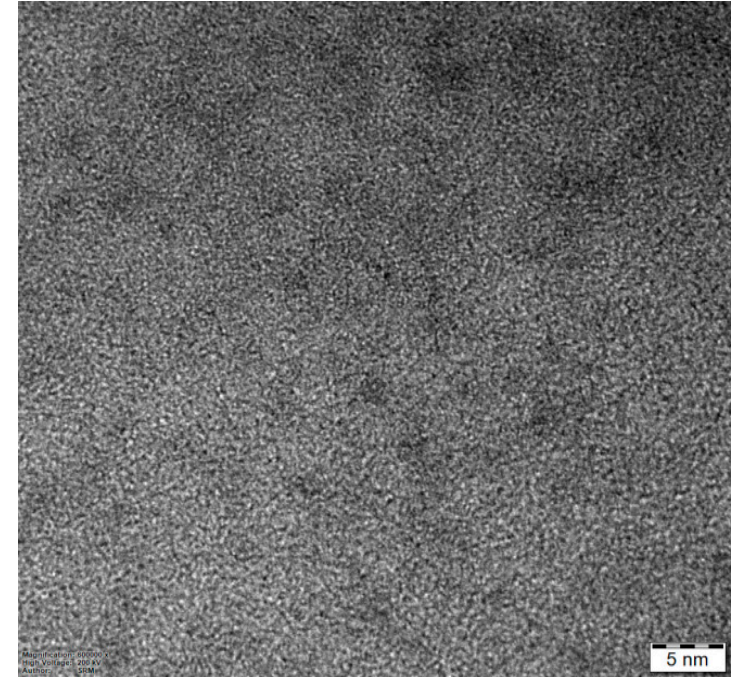

(c)

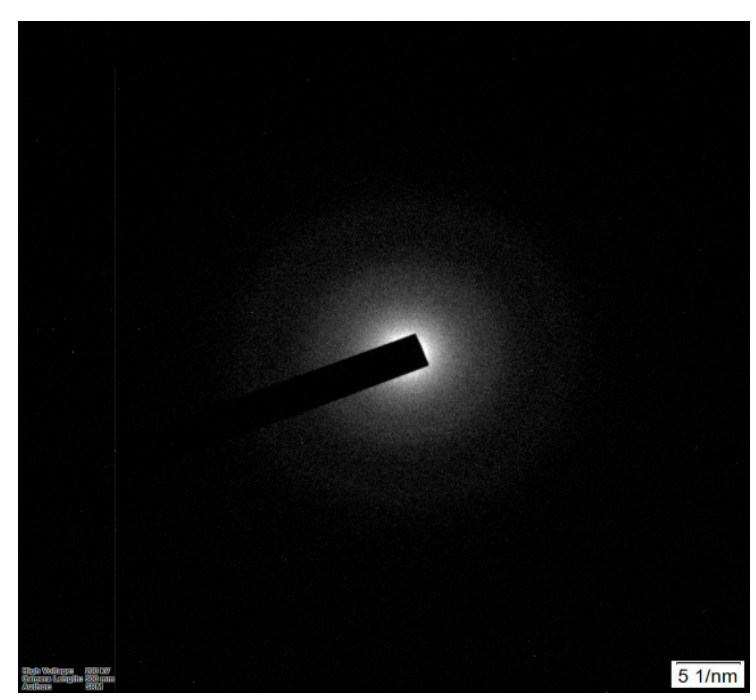

(d)

Figure 1. Transmission electron microscopy (TEM) images of the synthesized bismuth nanoparticles with image focus zoom $50 \mathrm{~nm}$ (a), $20 \mathrm{~nm}$ (b), and $5 \mathrm{~nm}$ (c). (d) selected area electron diffraction (SAED).

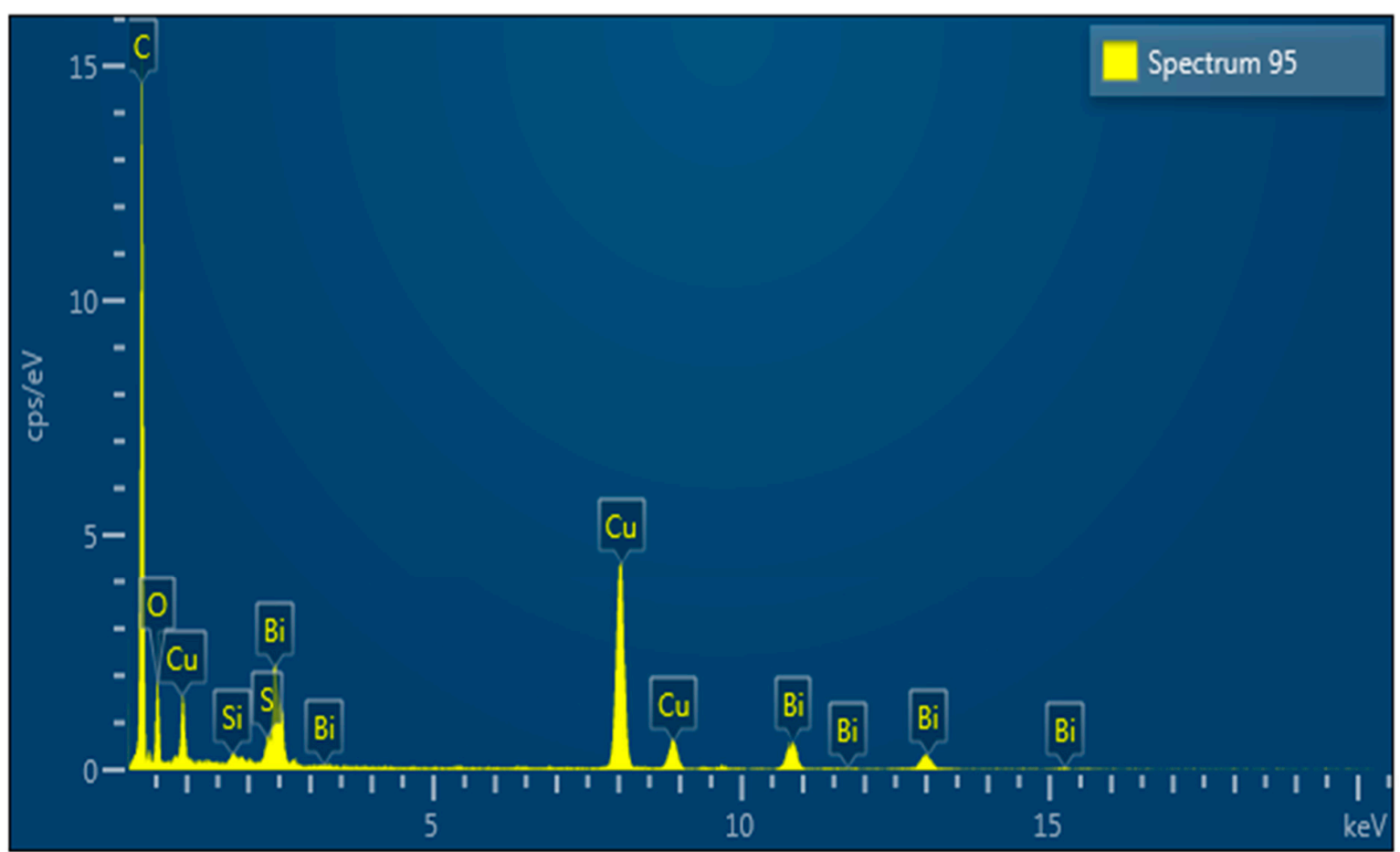

(a)

Figure 2. Cont. 


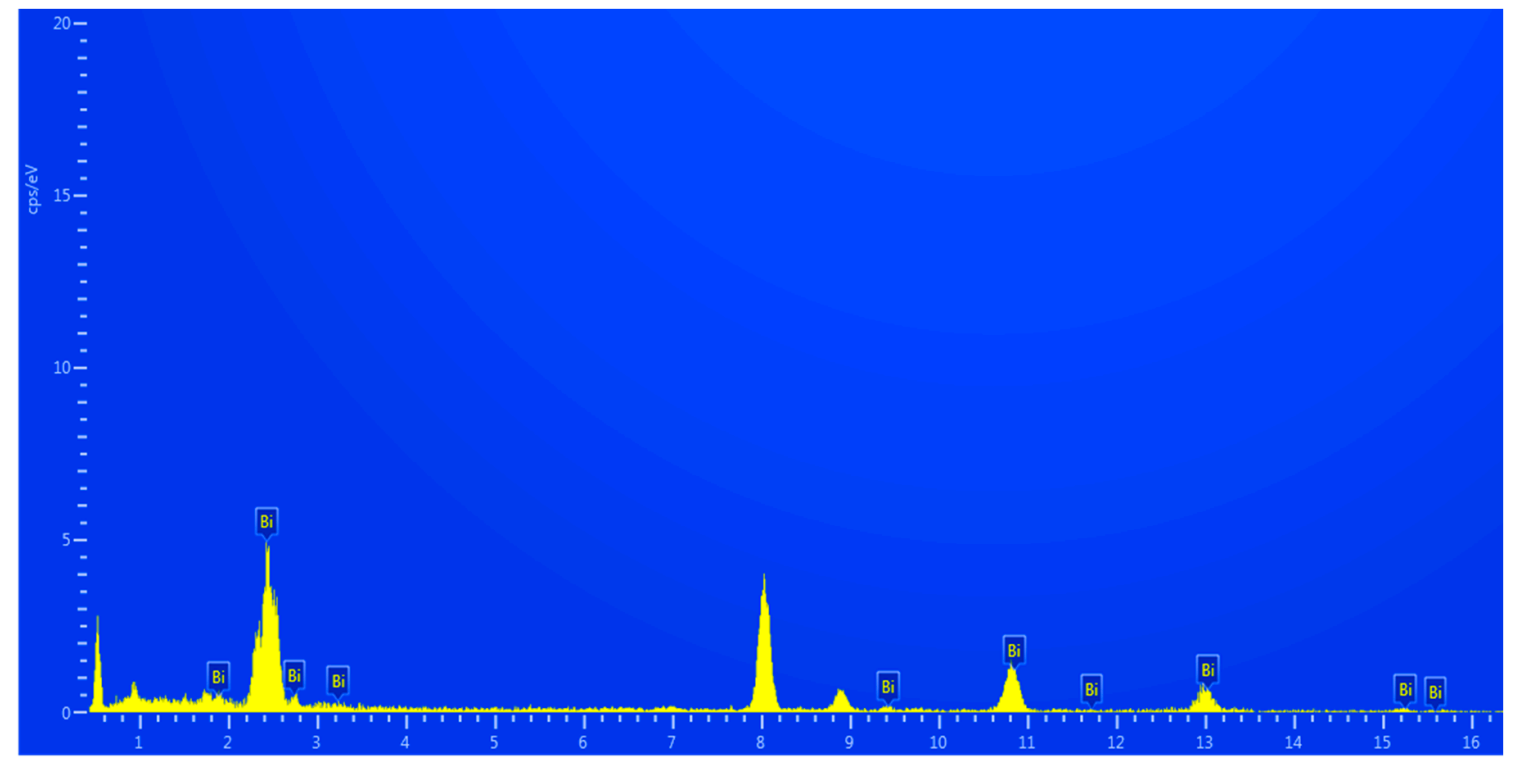

(b)

Figure 2. (a) Energy dispersive X-ray spectroscopy (EDS) spectrum for the region in Figure 1c, (b) EDS spectrum with peaks corresponding to bismuth.

The synthesized encapsulated bismuth nanoparticles were washed only with ethanol and water, to avoid the use of harsh chemicals and thermal processes. Figure 1a shows the phytochemicals in the extract enclosing the nanoparticles as dark spots in the cloud of organic matrix. The right lower part of Figure 1a was enlarged to $20 \mathrm{~nm}$ in Figure $1 \mathrm{~b}$ and further to $5 \mathrm{~nm}$ in Figure 1c. The selected area electron diffraction (SAED) of this portion was given in Figure 1d. The EDS, taken at the sample shown in Figure 1c, is given in Figure 2a,b.

Figure 2a,b presenting the counts at $2.469 \mathrm{KeV}$ and $10.839 \mathrm{KeV}$ correspond to the X-ray energies for bismuth $M \alpha$ and $L \alpha$ lines. The counts for bismuth come from the grid that holds the sample. The phytochemical matrix enclosing the sample explains the presence of other signals in the EDS. This indicates the presence of bismuth nanoparticles in the synthesized encapsulated nanoparticles and absence of other elements.

The synthesized bismuth nanoparticles were obtained in ethanol to give a colloidal solution. The electron diffraction pattern in Figure 1d explains the amorphous in nature of the product as nanoparticles agglomerate upon storage. EDS analysis (Figure 2) confirmed the presence of elemental bismuth nanoparticles. The absence of other elemental peaks reflects the purity of the sample. As shown in Figure 3a, the SEM images suggest an approximate size of the synthesized bismuth particles in the range of 40 and $60 \mathrm{~nm}$. It is envisaged to perform a TEM analysis to obtain the proper size of nanoparticles.

However, SEM analysis suggests that phytochemical encapsulated bismuth nanoparticles tend to agglomerate upon storage for one week, as seen in Figure 3b,c.

$X$-ray diffraction (XRD) analysis confirms the amorphous nature of the synthesized bismuth nanoparticles (Figure 4).

This substantiates the diffraction pattern observed in Figure 1d, suggesting that the synthesized bismuth nanoparticles are amorphous in morphology due to the presence of phytochemicals enclosing these nanoparticles. 


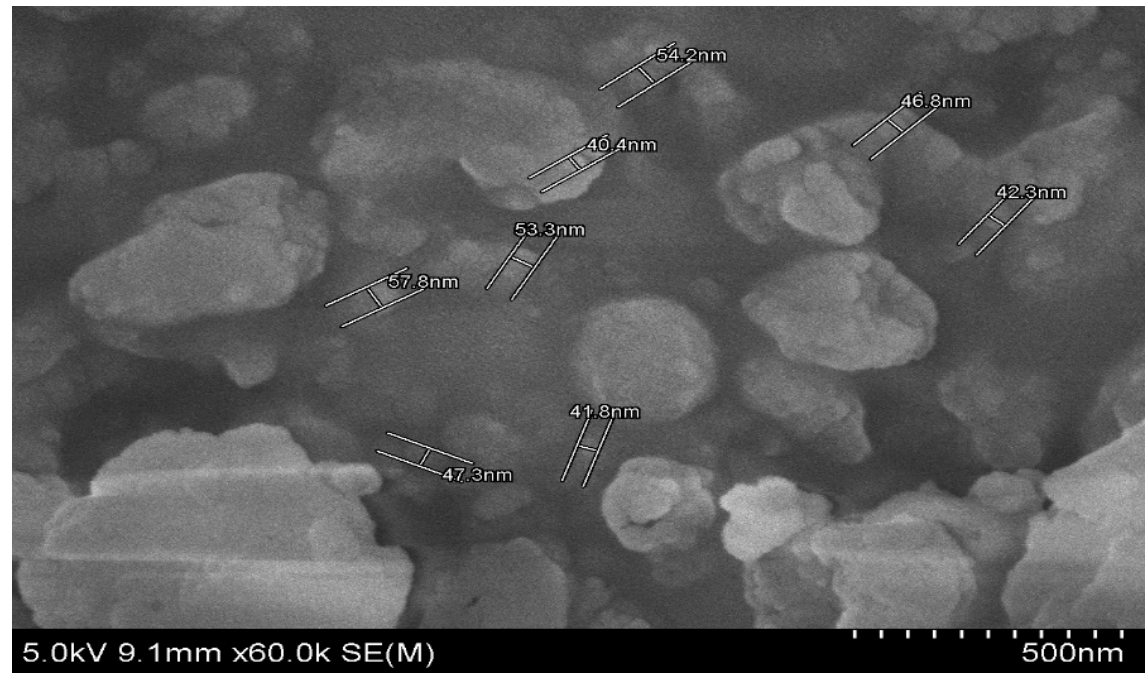

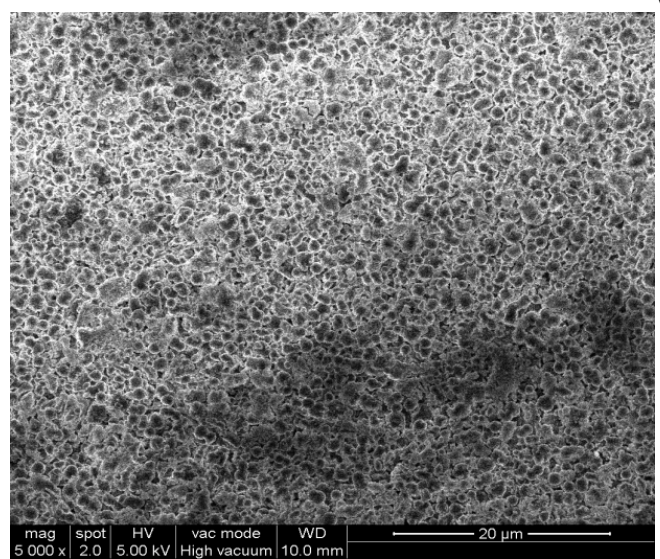

(b)

(a)

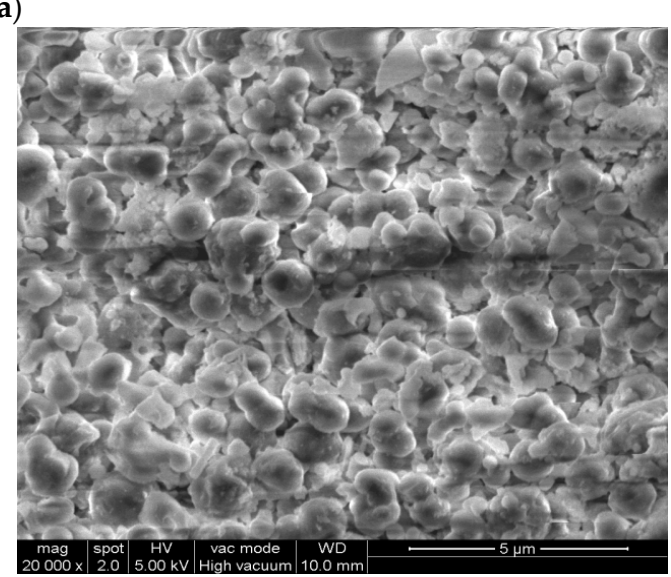

(c)

Figure 3. SEM image of the synthesized bismuth nanoparticles with image focus zoom $500 \mathrm{~nm}$ (a), $20 \mu \mathrm{M}(\mathbf{b})$, and $5 \mu \mathrm{M}(\mathbf{c})$.

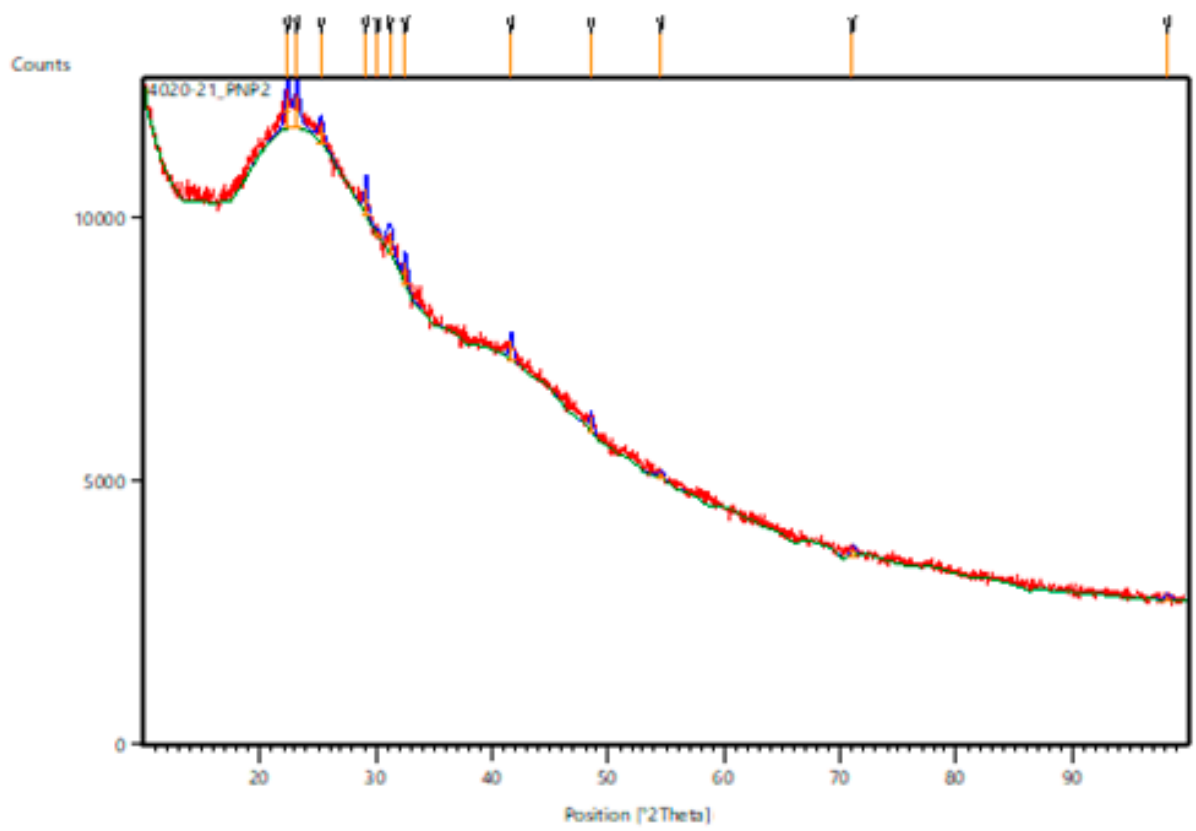

Figure 4. XRD spectrum of the synthesized bismuth nanoparticles. 
2.2.2. Fourier Transform Infrared Spectroscopy (FT-IR) of the M. oleifera Leaves Extract and the Synthesized Bismuth Nanoparticles

The FT-IR spectra of the M. oleifera leaves extract and the synthesized bismuth nanoparticles are shown in Figures 5 and 6, respectively. This vibration spectroscopy data can be used to identify the biomolecules implicated in the synthesis of bismuth nanoparticles. The bands around $3400 \mathrm{~cm}^{-1}$ and $1630 \mathrm{~cm}^{-1}$ are broad in the M. oleifera leaves extract (Figure 5), corresponding to the vibration mode of hydroxyl group, mostly found in polyphenolic molecules such as tannins, flavonoids, and glycoside derivatives. The FT-IR spectrum of the synthesized bismuth nanoparticles (Figure 6) depicts a sharp band at $3431 \mathrm{~cm}^{-1}$, corresponding to the $\mathrm{N}-\mathrm{H}$ vibration mode. The fingerprint region at $1269 \mathrm{~cm}^{-1}$ explains the binding of the organic matrix to the synthesized bismuth nanoparticles. This comparison reflects the participation of the hydroxyl group in the synthesis of bismuth nanoparticles. Moreover, the binding characteristics of amino groups in the M. oleifera leaves extract are observed in Figures 5 and 6 . This could be the reason for agglomeration of the synthesized bismuth nanoparticles to give an amorphous morphology.

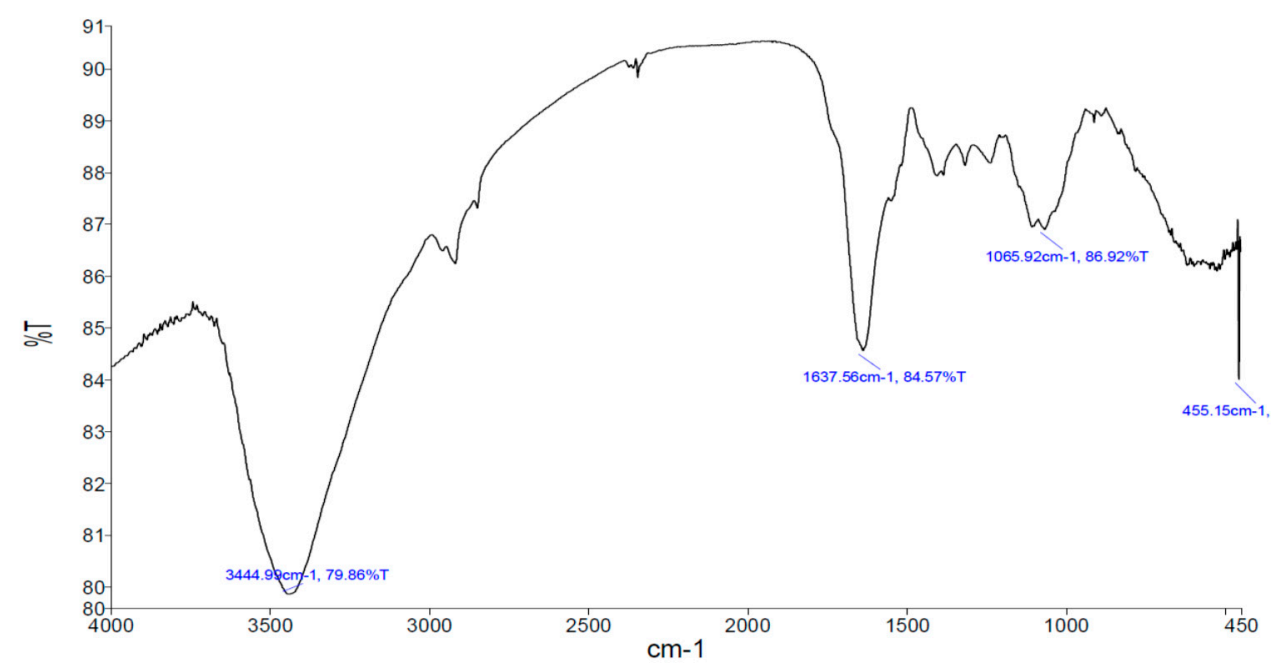

Figure 5. FT-IR spectrum of the M. oleifera leaves extract.

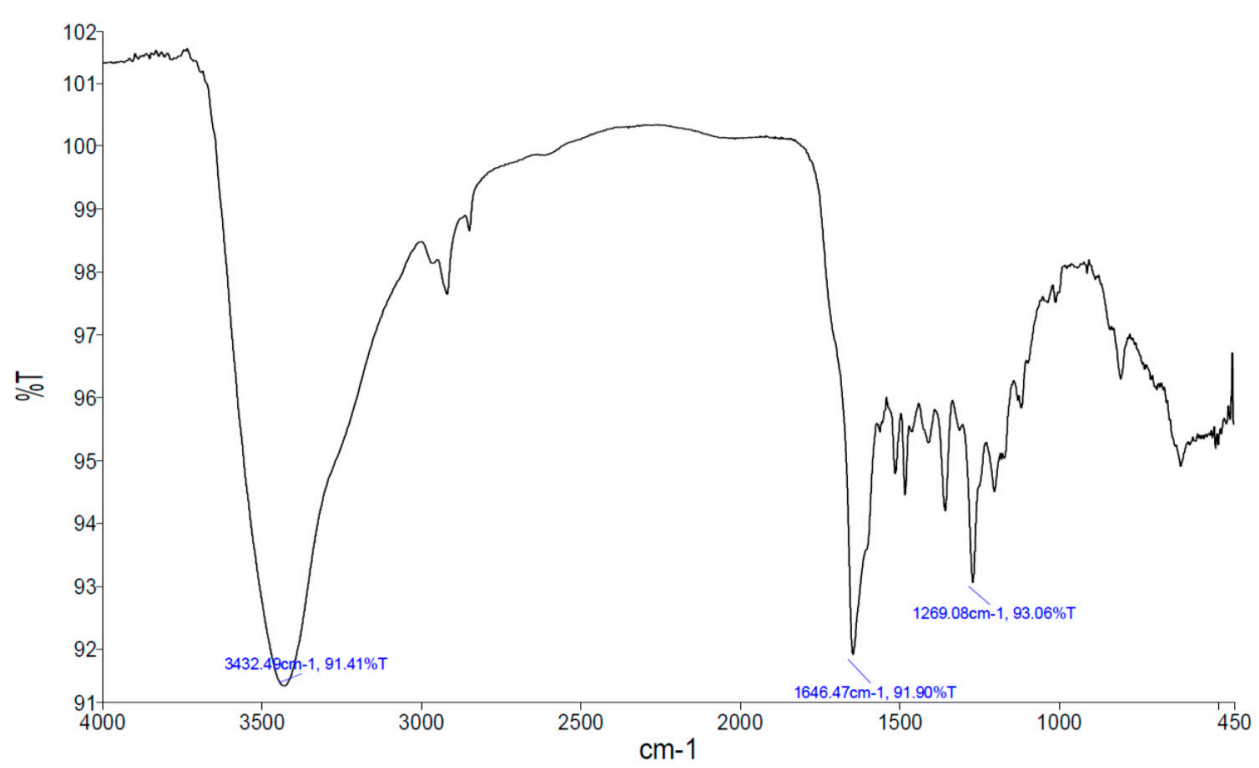

Figure 6. FT-IR spectrum of the synthesized bismuth nanoparticles. 
2.2.3. UV-Vis Spectroscopy of the M. oleifera Leaves Extract and the Synthesized Bismuth Nanoparticles

The UV-Vis absorption spectrum of the M. oleifera leaves extract is shown in Figure $7, \lambda_{\max }$ at $390 \mathrm{~nm}$. The UV-Vis spectrum of the synthesized bismuth nanoparticles reconstituted in dimethyl sulfoxide (DMSO) solvent is shown in Figure $8, \lambda_{\max }$ at $270 \mathrm{~nm}$. The peak relative to the phytochemicals is slightly decreased, due to changes in poly-hydroxyl compounds responsible for bio-reduction and the encapsulation of the product, and the peak maximum is shifted to the right. The phytochemical complexed with bismuth are enriched in the Figure 8, and the absorbance at 220 and could be terpenes or polyphenolic species.

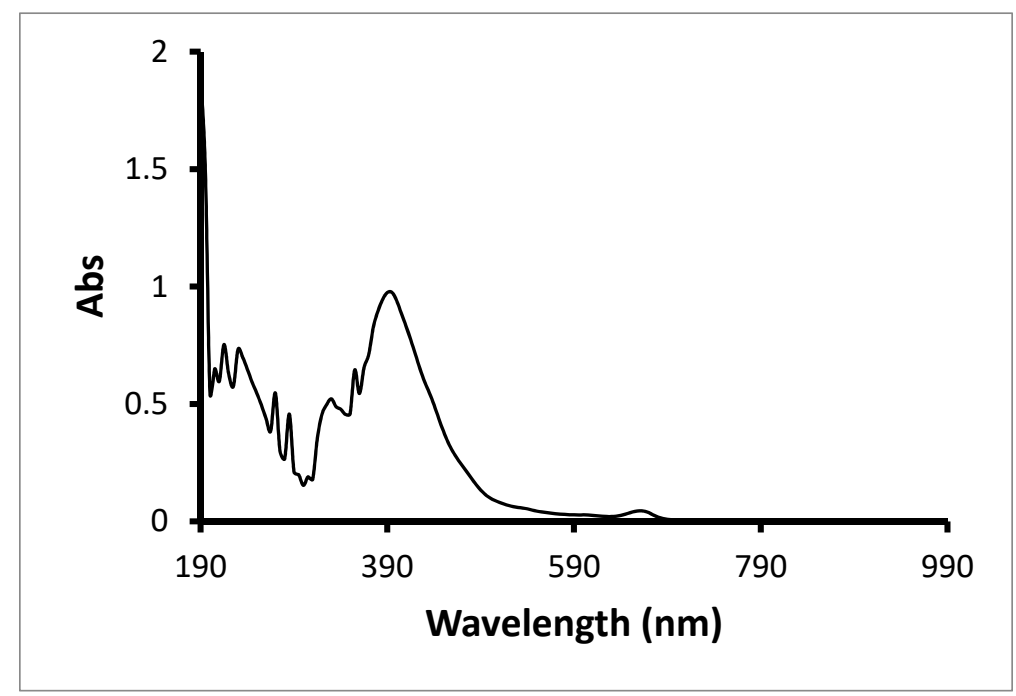

Figure 7. UV-Vis spectrum of the M. oleifera leaves extract.

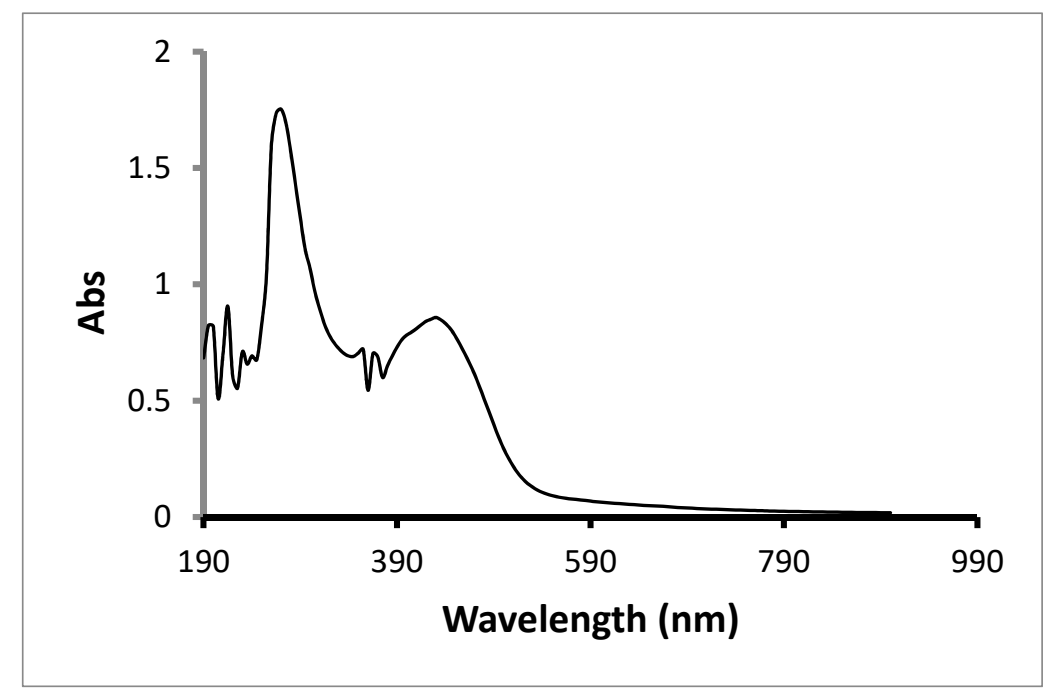

Figure 8. UV-Vis spectrum of the synthesized bismuth nanoparticles.

\subsection{Antioxidant Activity of the M. oleifera Leaves Extract and the Synthesized Bismuth Nanoparticles}

Using DPPH assay against ascorbic acid (standard), the antioxidant activity percentage (AA\%) of the M. oleifera leaves extract and the synthesized bismuth nanoparticles was assessed. As shown in Table 3, the M. oleifera leaves extract exerted considerable antioxidant potential, while the synthesized bismuth nanoparticles displayed relatively weaker antioxidant activity. These results were supported with total antioxidant capacity measured by phosphomolybdate assay (Table 4). 
Table 3. Antioxidant activity percentage (AA\%) using DPPH assay.

\begin{tabular}{cccccc}
\hline Sample & \multicolumn{5}{c}{ Amount $(\boldsymbol{\mu g})$} \\
\cline { 2 - 6 } & $\mathbf{1 0 0}$ & $\mathbf{2 0 0}$ & $\mathbf{3 0 0}$ & $\mathbf{4 0 0}$ & $\mathbf{5 0 0}$ \\
\hline Ascorbic acid (standard) & 34.4 & 55.1 & 67.2 & 75.8 & 84.4 \\
M. oleifera leaves extract & 55.1 & 58.6 & 63.7 & 65.5 & 65.5 \\
Bismuth nanoparticles & 25.8 & 37.9 & 37.9 & 48.2 & 60.3 \\
\hline
\end{tabular}

Table 4. Total antioxidant capacity (TAC) using phosphomolybdate assay.

\begin{tabular}{cccccc}
\hline \multirow{2}{*}{ Sample } & \multicolumn{5}{c}{ Concentration $(\mu \mathrm{g} / \mathrm{mL})$} \\
& $\mathbf{2 0 0}$ & $\mathbf{4 0 0}$ & $\mathbf{6 0 0}$ & $\mathbf{8 0 0}$ & $\mathbf{1 0 0 0}$ \\
\cline { 2 - 6 } & 130 & 260 & 410 & 530 & 690 \\
M. oleifera leaves extract & 50 & 50 & 50 & 60 & 60 \\
Bismuth nanoparticles & 50.04 Acid Equivalent) \\
\hline
\end{tabular}

\subsection{Anti-Bacterial Activity of the M. oleifera Leaves Extract and the Synthesized Bismuth Nanoparticles}

The potential anti-bacterial activity of synthesized bismuth nanoparticles was evaluated against four bacterial species (E. coli, K. pneumoniae, S. aureus, and E. faecalis). The classification of these species of bacteria and their localization in the human body is given in Table 5. The estimated minimum inhibitory concentration (MIC) values measured in presence of the M. oleifera leaves extract and the bismuth nanoparticles are given in Table 6. The growth of the indicated species of bacteria in the presence of different concentrations $(7.8-1000 \mu \mathrm{g} / \mathrm{mL})$ of $M$. oleifera leaves extract and the bismuth nanoparticles is shown in Table 7. The resazurin microtiter assay plates for the M. oleifera leaves extract and the synthesized bismuth nanoparticles are shown in Figure 9. In presence of the M. oleifera leaves extract, the estimated MIC values against E. coli, K. pneumoniae, S. aureus, and E. faecalis were found to be in the range of $250-500 \mu \mathrm{g} / \mathrm{mL}$ (Table 6). The estimated MIC values $(250-500 \mu \mathrm{g} / \mathrm{mL}$ ) in presence of the synthesized bismuth nanoparticles were similar to that of M. oleifera leaves extract (Table 6): the bismuth nanoparticles have comparable anti-bacterial activities (Table 6 and Figure 9), albeit a portion of the phytochemicals is complexed to the nanoparticles, as seen by the reduction in antioxidant power (Table 2). Hence, in the product bismuth nanoparticles, a reduction in TAC and AA \% was observed with loss of some functional group during transformation of the phytochemicals, responsible for bio-reduction and the encapsulation of nanoparticles. This loss may account also to the difference in inhibition found, on K. pneumoniae and S. aureus, and on Aspergillus species.

Table 5. Species of bacteria used for the anti-bacterial study.

\begin{tabular}{cccc}
\hline No. & Bacterial Species & Classification & Localization or Possible Infection Sites in the Human Body \\
\hline 1 & Escherichia coli & Gram-negative & Lower intestine \\
2 & Klebsiella pneumoniae & Gram-negative & Upper respiratory tract \\
3 & Staphylococcus aureus & Gram-positive & Upper respiratory tract \\
4 & Enterococcus faecalis & Gram-positive & Gastrointestinal tract \\
\hline
\end{tabular}

Table 6. Anti-bacterial activity (estimated MIC values) and anti-fungal activity (estimated MIC values).

\begin{tabular}{cccc}
\hline Bacterial Species & MIC $(\mu \mathrm{g} / \mathrm{mL})$ & Fungi & MIC $(\mu \mathrm{g} / \mathrm{mL})$ \\
\hline E. coli + M. oleifera extract & 500 & A. niger + M. oleifera extract & 62.5 \\
E. coli + M. oleifera Bismuth NPs & 500 & A. niger + M. oleifera Bismuth NPs & 250 \\
K. pneumoniae + M. oleifera extract & 250 & A. flavus + M. oleifera extract & 62.5 \\
K. pneumoniae + M. oleifera Bismuth NPs & 500 & A. flavus + M. oleifera Bismuth NPs & 250 \\
S. aureus + M. oleifera extract & 250 & C. albicans + M. oleifera extract & 125 \\
S. aureus + M. oleifera Bismuth NPs & 500 & C. albicans + M. oleifera Bismuth NPs & 62.5 \\
E. faecalis + M. oleifera extract & 250 & C. glabrata + M. oleifera extract & 250 \\
E. faecalis + M. oleifera Bismuth NPs & 250 & C. glabrata + M. oleifera Bismuth NPs & 62.5 \\
\hline
\end{tabular}


Table 7. Anti-bacterial activity data (growth (+) and no growth (-)).

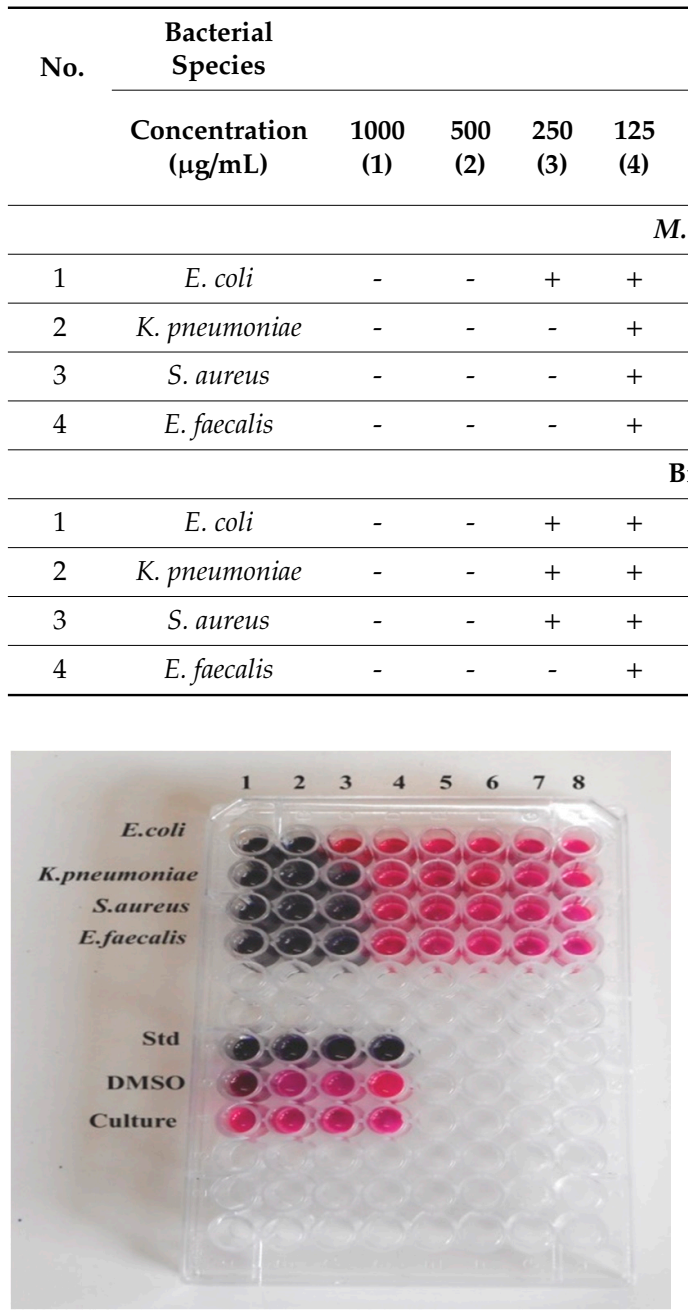

(a) M. oleifera leaves extract
Growth of Bacteria

\begin{tabular}{|c|c|c|c|c|c|}
\hline $\begin{array}{l}31.2 \\
(6)\end{array}$ & $\begin{array}{l}15.6 \\
(7)\end{array}$ & $\begin{array}{l}7.8 \\
(8)\end{array}$ & $\begin{array}{c}\text { Streptomycin } \\
(10 \mu \mathrm{g} / 500 \\
\mu \mathrm{L})\end{array}$ & $\begin{array}{c}\text { Negative } \\
\text { Control }\end{array}$ & $\begin{array}{l}\text { Nutrient } \\
\text { Broth }\end{array}$ \\
\hline
\end{tabular}

M. oleifera Leaves Extract

\begin{tabular}{|c|c|c|c|c|c|c|}
\hline+ & + & + & + & - & + & + \\
\hline+ & + & + & + & - & + & + \\
\hline+ & + & + & + & - & + & + \\
\hline+ & + & + & + & - & + & + \\
\hline \multicolumn{7}{|c|}{ Bismuth Nanoparticles } \\
\hline+ & + & + & + & - & + & + \\
\hline+ & + & + & + & - & + & + \\
\hline+ & + & + & + & - & + & + \\
\hline+ & + & + & + & - & + & + \\
\hline
\end{tabular}

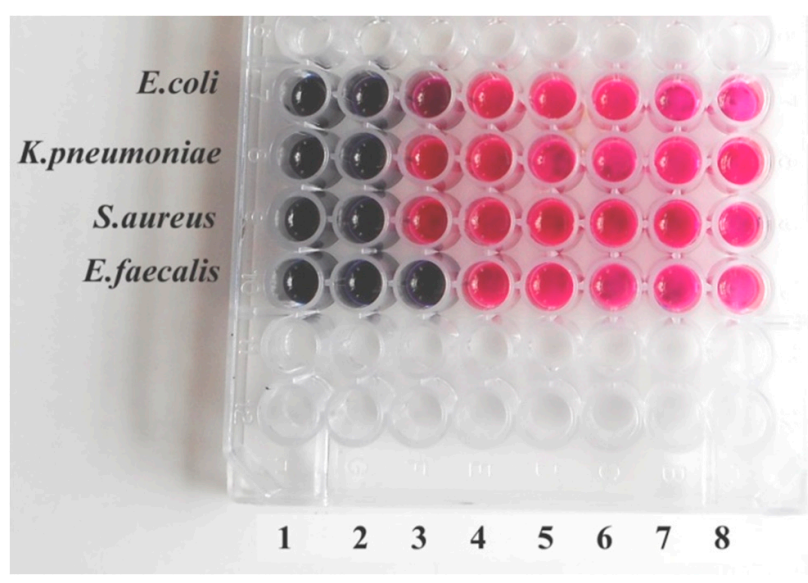

(b) Bismuth Nanoparticles

Figure 9. Resazurin microtiter assay plates for the antibacterial activity of $M$. oleifera leaves extract and the synthesized bismuth nanoparticles. (a) M. oleifera leaves extract, (b) Bismuth Nanoparticles.

\subsection{Anti-Fungal Activity of the M. oleifera Leaves Extract and the Synthesized Bismuth Nanoparticles}

The potential anti-fungal activity of synthesized bismuth nanoparticles was evaluated against four fungal species (A. niger, A. flavus, C. albicans, and C. glabrata). Ketoconazole $(10 \mu \mathrm{g} / 500 \mu \mathrm{L})$ was used as a positive control, while water-ethanol (1:1) solution and DMSO solvent served as negative controls for the M. oleifera leaves extract and the bismuth nanoparticles, respectively. The Potato Dextrose Broth was also used as a negative control. The classification of these species of fungi and their localization in the human body is given in Table 8 . The minimum inhibitory concentration (MIC) values measured in presence of the M. oleifera leaves extract and the bismuth nanoparticles are given in Table 6 . The growth of the indicated species of fungi in presence of different concentrations $(7.8-1000 \mu \mathrm{g} / \mathrm{mL})$ of M. oleifera leaves extract and the bismuth nanoparticles is shown in Table 9. The resazurin microtiter assay plates for the M. oleifera leaves extract and the synthesized bismuth nanoparticles are shown in Figure 10. In presence of the M. oleifera leaves extract, the estimated MIC values against $A$. niger, A. flavus, C. albicans, and C. glabrata were found to be $62.5,62.5,125$, and $250 \mu \mathrm{g} / \mathrm{mL}$, respectively (Table 6). In presence of the synthesized bismuth nanoparticles, the estimated MIC values against $A$. niger, A. flavus, C. albicans, and C. glabrata were found to be $250,250,62.5$, and $62.5 \mu \mathrm{g} / \mathrm{mL}$, respectively (Table 6). These findings indicate that the synthesized bismuth nanoparticles displayed more effective anti-fungal activity against $C$. albicans and C. glabrata compared to the M. oleifera leaves extract (Tables 6 and 9, and 
Figure 10). Candida species are normally present on human skin, and their infections are common in skin and other tissues due to dysbiosis and suppression of immune responses. Future in vivo analysis is required to shed light on the possible employment of the encapsulated phytochemical synthesized bismuth nanoparticles in the treatment of candidiasis, but we anticipate that they could serve as a promising therapeutic candidate to treat candidiasis after considering their pharmacokinetics.

Table 8. Species of fungi used for the anti-fungal study.

\begin{tabular}{ccc}
\hline No. & Fungal Species & Localization or Possible Infection Sites in the Human Body \\
\hline 1 & Aspergillus niger & Lungs \\
\hline 2 & Aspergillus flavus & Lungs, eyes, and ears \\
\hline 3 & Candida albicans & Gastrointestinal tract and mucosal tissues \\
\hline 4 & Candida glabrata & Mucosal tissues \\
\hline
\end{tabular}

Table 9. Anti-fungal activity data (growth (+) and no growth (-)).

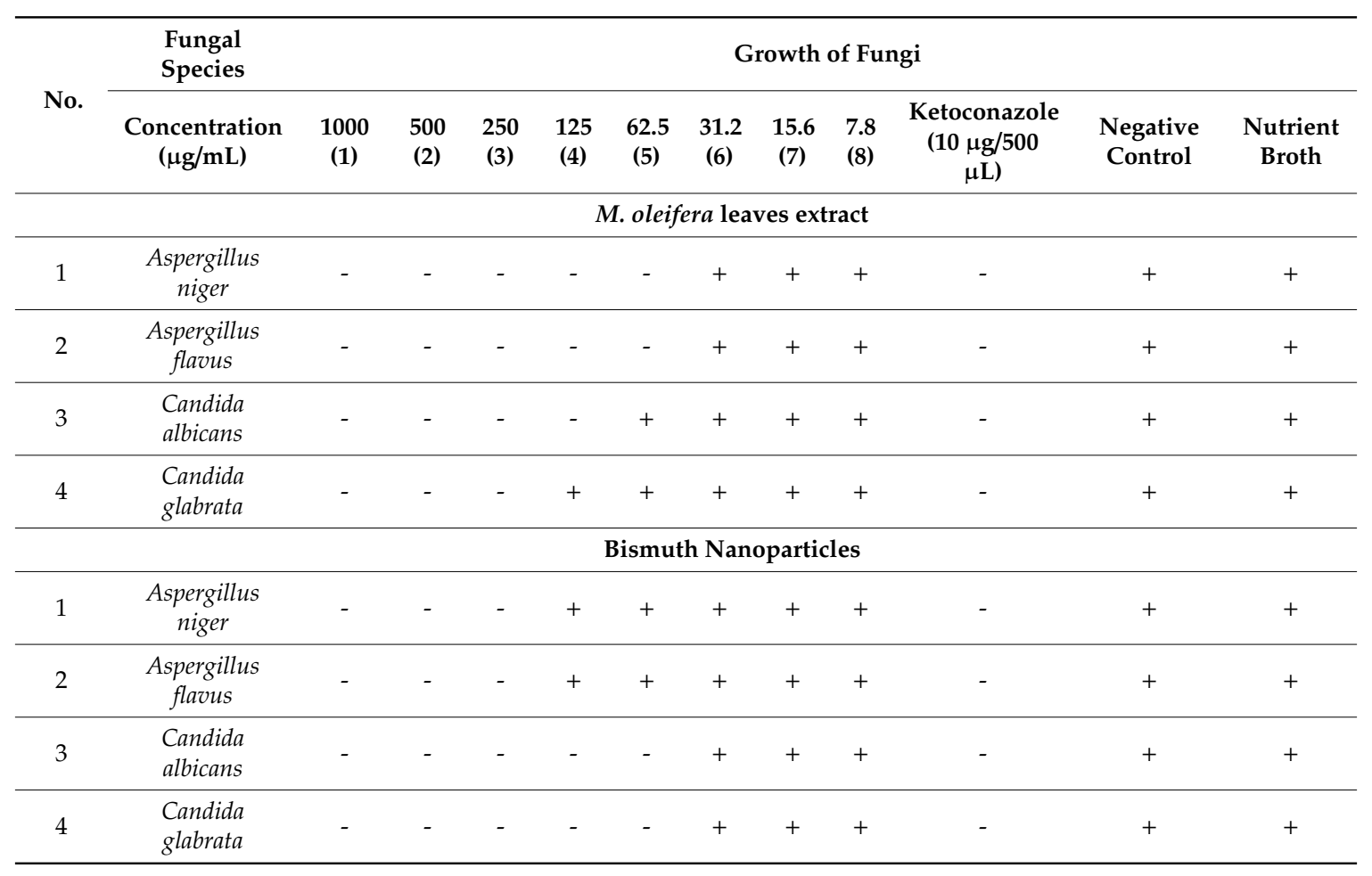




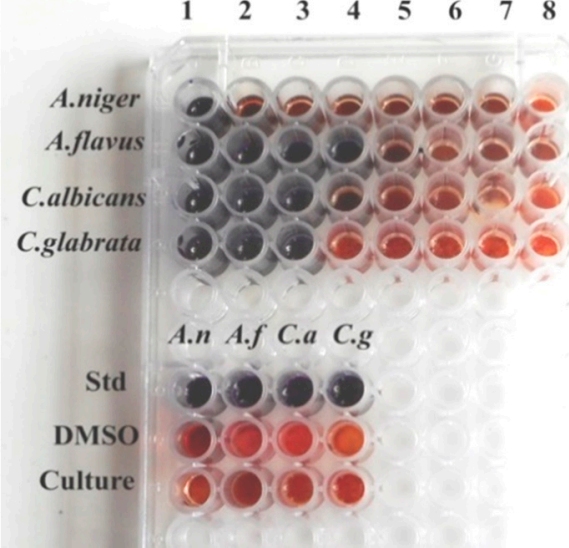

(a) M. oleifera leaves extract

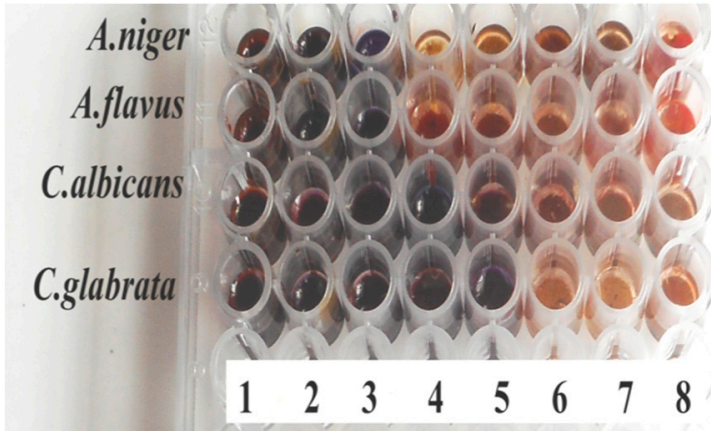

(b) Bismuth nanoparticles

Figure 10. Resazurin microtiter assay plates for the antifungal activity of $M$. oleifera leaves extract and the synthesized bismuth nanoparticles. (a) M. oleifera leaves extract, (b) Bismuth nanoparticles.

\section{Materials and Methods}

\subsection{Preparation of the M. oleifera Leaves Extract}

The leaves of M. oleifera were collected from the wild shrub regions in Rajapalayam, Tamil Nadu, India. The plant was identified by the facility at Asthagiri Herbal Research Foundation, Chennai, India. The identified specimen vouchers (AHRF/HERBARIUM/021) were deposited at Asthagiri Herbal Research Foundation, Chennai, India. The country's common breed was used in the study. The genetically-modified varieties of $M$. oleifera (PKM-1 and PKM-2) were not used in our study. Fresh M. oleifera leaves were collected and shade-dried. The dried leaves were smoothly crushed. The M. oleifera leaves powder was stored at room temperature. A total of $10 \mathrm{~g}$ of $\mathrm{M}$. oleifera leaves powder was taken and soaked in $100 \mathrm{~mL}$ water-ethanol (1:1) solution. The mixture was macerated for $1 \mathrm{~h}$ and the M. oleifera leaves extract was filtered through Whatman filter paper 1 . The M. oleifera leaves extract was used immediately for the preparation of bismuth nanoparticles and other experimental analyses.

\subsection{Synthesis of the Bismuth Nanoparticles}

Bismuth nitrate pentahydrate $(1 \mathrm{~g})$ was dissolved in $20 \mathrm{~mL}$ de-mineralized water and added to $80 \mathrm{~mL}$ of $M$. oleifera leaves extract. The reaction mixture was stirred for $3 \mathrm{~h}$ at $60{ }^{\circ} \mathrm{C}$. The synthesized bismuth nanoparticles were collected by using centrifugation and repeatedly washed with de-mineralized water. The encapsulated phytochemical synthesized bismuth nanoparticles were dried at $105{ }^{\circ} \mathrm{C}$ for $1 \mathrm{~h}$, and subsequently reconstituted in DMSO solvent.

\subsection{Characterization of the Size and Morphology of the Synthesized Bismuth Nanoparticles}

The completion of synthesis was characterized using a UV-3600 Plus UV-Vis double beam spectrophotometer (Shimadzu, Kyoto, Japan). The formation of bismuth nanoparticles and the role of biomolecules in this synthesis were confirmed using an ALPHA-E FTIR spectrometer (Bruker, Billerica, MA, USA). The crystalline nature of the synthesized bismuth nanoparticles was ascertained by XRD using a XRD-6000 diffractometer (Shimadzu, Kyoto, Japan). The size of the synthesized bismuth nanoparticles was measured by SEM using a FEI Quanta 200 scanning electron microscope, with the field emission gun (FEG) feature for better resolution (ThermoFisher Scientific, Waltham, MA, USA). The morphology assessment of the synthesized nanoparticles was performed by transmission electron microscopy (TEM) using a JEOL-TEM-2100 plus transmission electron microscopy (JEOL, Tokyo, Japan). The sample was dispersed in ethanol, coated on the grid, and dried for TEM analysis along with EDS analysis. In previous published work, several authors described improvement of silver nanoparticles, by means of a nitroxide coating to make silver NPs [43], through immobilization of 
TEMPO moieties on the surface of various materials and synthesis of novel hybrid nanostructures [44], and through synthesis of gold nanoparticles densely coated with nitroxide spins [45]. Although this is a preliminary work, in the next step we will perform thermogravimetric and XPS analyses to give a proper characterization of the synthesized materials and to assess the content of bismuth in the synthesized materials. We will deepen study of this area by applying this method in the future research. We are confident that the antifungal activity toward Candida species may provide a temporary therapeutic application.

\subsection{Phytochemical Analysis of the M. oleifera Leaves Extract}

The qualitative analysis of biomolecules present in the M. oleifera leaves extract was carried out for the presence of alkaloids, tannins, flavonoids, steroids, saponins, polyphenols, glycosides, carbohydrates, proteins, and amino acids. The total phenolic content in the M. oleifera leaves extract was estimated as gallic acid equivalent by Folin-Ciocalteu polyphenol assay [46]. The protein content in the M. oleifera leaves extract was estimated by using Lowry's method [47].

\subsection{Antioxidant Activity}

\subsubsection{DPPH Assay (Antioxidant Activity Percentage-AA\%)}

The antioxidant activity percentage (AA\%) (scavenging activity) of the M. oleifera leaves extract and the synthesized bismuth nanoparticles was assessed by using DPPH free radical scavenging assay. A total of $1 \mathrm{mg}$ of ascorbic acid (standard) was dissolved in $1 \mathrm{~mL}$ of methanol. Different aliquots (serial dilution) of the ascorbic acid solution $(0.1-0.5 \mathrm{~mL}$ ), corresponding to $100-500 \mu \mathrm{g}$, were used for calibration. To each tube containing ascorbic acid solution, $1 \mathrm{~mL}$ of $0.1 \mathrm{mM}$ DPPH radical solution in ethanol was added, and the final volume was adjusted to $4 \mathrm{~mL}$ using ethanol. The stock solutions for the M. oleifera leaves extract and the synthesized bismuth nanoparticles were prepared by dissolving $1 \mathrm{mg}$ of each sample in $1 \mathrm{~mL}$ of an appropriate solvent (methanol for the M. oleifera leaves extract; DMSO for the synthesized bismuth nanoparticles). Different aliquots from the stock solutions $(0.1-0.5 \mathrm{~mL})$, corresponding to 100-500 $\mu \mathrm{g}$, were added to all tubes except the blank tube (control). The volume in each tube was adjusted to $3 \mathrm{~mL}$ using ethanol. A total of $1 \mathrm{~mL}$ of $0.1 \mathrm{mM}$ DPPH radical solution in ethanol was added to each tube,. The blank tube (control) was prepared by mixing $3 \mathrm{~mL}$ of ethanol and $1 \mathrm{~mL}$ of DPPH radical solution in ethanol. All tubes were incubated for $30 \mathrm{~min}$ at room temperature, and absorbance at $517 \mathrm{~nm}$ was recorded. AA \% was determined using the following formula:

$$
\mathrm{AA} \%=\{(\text { absorbance of blank })-(\text { absorbance of sample }) /(\text { absorbance of blank })\} \times 100
$$

\subsubsection{Phosphomolybdenum Assay (Total Antioxidant Capacity-TAC)}

The total antioxidant capacity (TAC) of the M. oleifera leaves extract and the synthesized bismuth nanoparticles was assessed by phosphomolybdenum assay as ascorbic acid equivalent. A total of $1 \mathrm{mg}$ of ascorbic acid (standard) was dissolved in $1 \mathrm{~mL}$ of methanol. Different aliquots (serial dilution) of the ascorbic acid solution $(0.1-0.5 \mathrm{~mL})$, corresponding to $100-500 \mu \mathrm{g}$, were prepared. The volume in each tube was adjusted to $4 \mathrm{~mL}$ using distilled water. The stock solutions for the $M$. oleifera leaves extract and the synthesized bismuth nanoparticles were prepared by dissolving $1 \mathrm{mg}$ of each sample in $1 \mathrm{~mL}$ of an appropriate solvent (methanol for the M. oleifera leaves extract; DMSO for the synthesized bismuth nanoparticles). Different aliquots from the stock solutions $(0.1-0.5 \mathrm{~mL})$, corresponding to $100-500 \mu \mathrm{g}$, were added to all tubes except the blank tube (control). The volume in each tube was adjusted to $3 \mathrm{~mL}$ using distilled water. To each tube, $1 \mathrm{~mL}$ of phosphomolybdenum reagent $(0.6 \mathrm{M}$ sulfuric acid, $28 \mathrm{mM}$ sodium phosphate, and $4 \mathrm{mM}$ ammonium molybdate) was added. The volume in each tube was adjusted to $4 \mathrm{~mL}$ using distilled water. After incubation for $90 \mathrm{~min}$ at $95^{\circ} \mathrm{C}$, absorbance at $695 \mathrm{~nm}$ was recorded. The calibration curve for the ascorbic acid solution (standard) was plotted for the absorbance at $695 \mathrm{~nm}$ against known amounts of ascorbic acid with the phosphomolybdate 
reagent in order to express the TAC values as ppm equivalent of ascorbic acid. Using the ascorbic acid calibration curve, the TAC values for the $M$. oleifera leaves extract and the synthesized bismuth nanoparticles were calculated and expressed as a ppm equivalent of ascorbic acid.

\subsection{Anti-Bacterial Activity using Resazurin Microtiter Assay}

The bacterial cultures of E. coli, K. pneumoniae, S. aureus, and E. faecalis were obtained from the Royal Bio Research Centre, Chennai, Tamil Nadu, India.The most rapid and inexpensive way to screen several microorganism isolates at the same time, with better correlation in comparison to other techniques, is the resazurin microtiter assay [48-50]. The resazurin solution was prepared by dissolving a $270 \mathrm{mg}$ tablet of resazurin in $40 \mathrm{~mL}$ of sterile distilled water. The test was carried out in 96-well plates under aseptic conditions. A volume of $100 \mu \mathrm{L}$ of sample containing $10 \mathrm{mg} / \mathrm{mL}$ was transferred into the first well of the plate. Afterwards, $50 \mu \mathrm{L}$ of nutrient broth was added to all other wells, and the tested sample was serially diluted. Subsequently, $10 \mu \mathrm{L}$ of resazurin solution and $10 \mu \mathrm{L}$ of bacterial suspension were added to each well. To prevent dehydration, the plates were wrapped with cling film and incubated at $37^{\circ} \mathrm{C}$ for $18-24 \mathrm{~h}$. The color change was visually observed. A purple to pink (or colorless) color change was considered as being positive, indicating cell growth (i.e., (+) means growth and (-) means no growth). MIC was recorded at the lowest concentration whereby a color change occurred. Streptomycin $(10 \mu \mathrm{g} / 500 \mu \mathrm{L})$ served as a positive control, while water-ethanol (1:1) solution and DMSO solvent were used as negative controls for the M. oleifera leaves extract and the bismuth nanoparticles, respectively. The nutrient broth was also used as a negative control.

\subsection{Anti-Fungal Activity Using Resazurin Microtiter Assay}

The fungal cultures of A. niger, A. flavus, C. albicans, and C. glabrata were obtained from the Royal Bio Research Centre, Chennai, Tamil Nadu, India.The resazurin microtiter assay was performed as described above (Section 3.6). Ketoconazole $(10 \mu \mathrm{g} / 500 \mu \mathrm{L})$ was used as a positive control, while water-ethanol (1:1) solution and DMSO solvent served as negative controls for the M. oleifera leaves extract and the bismuth nanoparticles, respectively. The Potato Dextrose Broth was also used as a negative control.

\section{Conclusions}

Our experimental approach led to the successful green synthesis of bismuth nanoparticles using a hydroalcoholic extract of $M$. oleifera leaves. UV-Vis absorption and FT-IR spectrometry confirmed the formation of bismuth nanoparticles and the role of different biomolecules present in the M. oleifera leaves extract in the synthesis of bismuth nanoparticles. The presence of elemental bismuth was affirmed by EDS analysis. XRD analysis confirmed the crystalline nature of the synthesized bismuth nanoparticles. SEM analysis revealed that the size of the synthesized bismuth nanoparticles is in the range of 40.4-57.8 $\mathrm{nm}$. As revealed by TEM with EDS, the synthesized bismuth nanoparticles were confirmed to display an amorphous morphology. DPPH and phosphomolybdenum assays revealed that both the $M$. oleifera leaves extract and the synthesized bismuth nanoparticles exert considerable antioxidant activity. However, the antioxidant potential of the synthesized bismuth nanoparticles is weaker than that of the M. oleifera leaves extract, most likely due to a loss of some phenolic constituents. Our study further demonstrated that the $M$. oleifera leaves extract and the synthesized bismuth nanoparticles play a potent anti-bacterial role against E. coli, K. pneumoniae, S. aureus, and E. faecalis (MIC values for the extract: 500, 250, 250, and $250 \mu \mathrm{g} / \mathrm{mL}$; MIC values for the bismuth nanoparticles: $500,500,500$, and $250 \mu \mathrm{g} / \mathrm{mL}$, respectively), with a more profound inhibitory effect of the bismuth nanoparticles, compared to the $M$. oleifera leavesextract, against $E$. faecalis. Moreover, our findings also revealed that the $M$. oleifera leaves extract and the synthesized bismuth nanoparticles display relatively stronger anti-fungal activity against A. niger, A. flavus, C. albicans, and C. glabrata (MIC values for the extract: 62.5, 62.5, 125, and $250 \mu \mathrm{g} / \mathrm{mL}$; MIC values for the bismuth nanoparticles: 250, $250,62.5$, and $62.5 \mu \mathrm{g} / \mathrm{mL}$, respectively), with a promising and exploitable inhibitory activity against 
Candida species. This indicates that the anti-fungal effects of the $M$. oleifera leaves extract against A. niger and A. flavus is stronger than that of the synthesized bismuth nanoparticles, while the latter exerts more potent anti-fungal effects on C. albicans and C. glabrata. Obviously, our green synthesis approach to obtain bismuth nanoparticles using a hydroalcoholic extract of $M$. oleifera leaves did not jeopardize the bismuth nanoparticles' anti-bacterial and anti-fungal activities. Collectively, our study implies that the synthesized bismuth nanoparticles can be potentially used in the amelioration of oxidative stress and various microbial infections. In particular, the synthesized bismuth nanoparticles seem to be powerful anti-fungal agents against cases of candidiasis including, but not limited to oral thrush, urinary yeast infection, genital infection, intra-abdominal candidiasis, acute hematogenous candidiasis, fungemia, invasive candidiasis, endocarditis, and endophthalmitis. One advantage of green synthesis of nanoparticles is that it yields non-toxic products and it reduces the production of wasteful material. Another advantage of green synthesis of nanoparticles is that the encapsulating material being polyphenols has a therapeutic value compared to the incinerated nanoparticles that are synthesized by using conventional thermal-chemical methods.

Supplementary Materials: The following are available online at http://www.mdpi.com/1996-1944/13/4/876/s1, Figure S1: Chemical structures of caffeoylquinic acid, feruloylquinic acid, tannins, gallic acid, quercetin, kaempferol.

Author Contributions: S.N., I.A.A.-Y., A.F.M., and P.P. designed the experiments and supervised their execution. P.E.D. performed the preparation of the M. oleifera leaves extract and the green synthesis of the bismuth nanoparticles. P.E.D. performed the phytochemical and biological analyses. P.E.D., S.N., I.A.A.-Y., A.F.M., and P.P. performed data analyses of the experimental assays. All authors contributed to manuscript writing and preparation. All authors have read and agree to the published version of the manuscript.

Funding: This research was funded by MNRE (Project No. 31/03/2014-15/PVSE-R\&D), Government of India.

Acknowledgments: We acknowledge the HRTEM Facility at SRMIST set up with support from MNRE (Project No. 31/03/2014-15/PVSE-R\&D), Government of India. We acknowledge the Nanotechnology Research Centre (NRC), SRMIST for providing the research facilities.

Conflicts of Interest: The authors declare no conflicts of interest.

\section{References}

1. Rathi, B.S.; Bodhankar, S.L.; Baheti, A.M. Evaluation of aqueous leaves extract of Moringa oleifera Linn for wound healing in albino rats. Indian J. Exp. Biol. 2006, 44, 898-901. [PubMed]

2. Ogbe, A.O.; Affiku, J.P. Proximate study, mineral and anti-nutrient composition of Moringa oleifera leaves harvested from Lafia, Nigeria: Potential benefits in poultry nutrition and health. JMBFS 2011, 1, 296-308.

3. Siddhuraju, P.; Becker, K. Antioxidant properties of various solvent extracts of total phenolic constituents from three different agroclimatic origins of drumstick tree (Moringa oleifera Lam.) leaves. J. Agric. Food Chem. 2003, 51, 2144-2155. [CrossRef] [PubMed]

4. Fitzgerald, D.J.; Stratford, M.; Gasson, M.J.; Ueckert, J.; Bos, A.; Narbad, A. Mode of antimicrobial action of vanillin against Escherichia coli, Lactobacillus plantarum and Listeria innocua. J. Appl. Microbiol. 2004, 97, 104-113. [CrossRef] [PubMed]

5. Narasimhan, S.; Maheshwaran, S.; Abu-Yousef, I.A.; Majdalawieh, A.F.; Rethavathi, J.; Das, P.E.; Poltronieri, P. Anti-bacterial and anti-fungal activity of xanthones obtained via semi-synthetic modification of $\alpha$-mangostin from Garcinia mangostana. Molecules 2017, 22, 275. [CrossRef] [PubMed]

6. Suwantong, O.; Pankongadisak, P.; Deachathai, S.; Supaphol, P. Electrospun poly(l-lactic acid) fiber mats containing crude Garcinia mangostana extracts for use as wound dressings. Polym. Bull. 2014, 71, 925-949. [CrossRef]

7. Lakouraj, M.M.; Rahpaima, G.; Mohseni, M. Synthesis, characterization, metal sorption, and biological activities of organosoluble and thermally stable azoxanthone-based polyester. Polym. Adv. Technol. 2015, 26, 234-244. [CrossRef]

8. Mun, S.H.; Joung, D.K.; Kim, Y.S.; Kang, O.H.; Kim, S.B.; Seo, Y.S.; Kwon, D.Y. Synergistic antibacterial effect of curcumin against methicillin-resistant Staphylococcus aureus. Phytomedicine 2013, 20, 714-718. [CrossRef] 
9. Dogra, N.; Choudhary, R.; Kohli, P.; Haddock, J.D.; Makwana, S.; Horev, B.; Vinokur, Y.; Droby, S.; Rodov, V. Polydiacetylene nanovesicles as carriers of natural phenylpropanoids for creating antimicrobial food-contact surfaces. J. Agric. Food Chem. 2015, 63, 2557-2565. [CrossRef]

10. Ravichandran, M.; Hettiarachchy, N.S.; Ganesh, V.; Ricke, S.C.; Singh, S. Enhancement of antimicrobial activities of naturally occurring phenolic compounds by nanoscale delivery against Listeria monocytogenes, Escherichia coli O157:H7 and Salmonella Typhimurium in broth and chicken meat system. J. Food Saf. 2011, 31, 462-471. [CrossRef]

11. Horev, B.; Sela, S.; Vinokur, Y.; Gorbatsevich, E.; Pinto, R.; Rodov, V. The effects of active and passive modified atmosphere packaging on the survival of Salmonella enterica serotype Typhimurium on washed romaine lettuce leaves. Food Res. Int. 2012, 45, 1129-1132. [CrossRef]

12. Fadida, T.; Kroupitski, Y.; Peiper, U.M.; Bendikov, T.; Sela, S.; Poverenov, E. Air-ozonolysis to generate contact active antimicrobial surfaces: Activation of polyethylene and polystyrene followed by covalent graft of quaternary ammonium salts. Colloids Surf. B Biointerfaces 2014, 122, 294-300. [CrossRef] [PubMed]

13. Meridor, D.; Gedanken, A. Preparation of enzyme nanoparticles and studying the catalytic activity of the immobilized nanoparticles on polyethylene films. Ultrason. Sonochem. 2013, 20, 425-431. [CrossRef] [PubMed]

14. Reidy, B.; Haase, A.; Luch, A.; Dawson, K.A.; Lynch, I. Mechanisms of silver nanoparticle release, transformation and toxicity: A critical review of current knowledge and recommendations for future studies and applications. Materials 2013, 6, 2295-2350. [CrossRef]

15. Malka, E.; Perelshtein, I.; Lipovsky, A.; Shalom, Y.; Naparstek, L.; Perkas, N.; Patick, T.; Lubart, R.; Nitzan, Y.; Banin, E.; et al. Eradication of multi-drug resistant bacteria by a novel $\mathrm{Zn}$-doped $\mathrm{CuO}$ nanocomposite. Small 2013, 9, 4069-4076. [CrossRef]

16. Borase, H.P.; Salunke, B.K.; Salunkhe, R.B.; Patil, C.D.; Hallsworth, J.E.; Kim, B.S.; Patil, S.V. Plant extract: A promising bio-matrix for ecofriendly, controlled synthesis of silver nanoparticles. Appl. Biochem. Biotechnol. 2014, 17, 1-29. [CrossRef]

17. Park, Y. A new paradigm shift for the green synthesis of antibacterial silver nanoparticles utilizing plant extracts. J. Korean Soc. Toxicol. Res. 2014, 30, 169-178. [CrossRef]

18. Mohanta, Y.K.; Panda, S.K.; Jayabalan, R.; Sharma, N.; Bastia, A.K.; Mohanta, T.K. Antimicrobial, antioxidant and cytotoxic activity of silver nanoparticles synthesized by leaf extract of Erythrina suberosa (Roxb.). Front. Mol. Biosci. 2017, 4, 14. [CrossRef]

19. Madhavaraj, L.; Sethumadhavan, V.V.; Geun, H.G.; Mathur, N.K.; Si, W.K. Synthesis, characterization and evaluation of antimicrobial efficacy of silver nanoparticles using Paederia foetida leaf extract. Int. Res. J. Biol. Sci. 2013, 15, 76-80.

20. Krishnaraj, C.; Jagan, E.G.; Rajasekar, S.; Selvakumar, P.; Kalaichelvan, P.T.; Mohan, N. Synthesis of silver nanoparticles using Acalypha indica leaf extracts and its antibacterial activity against water borne pathogens. Colloids Surf. B Biointerfaces 2010, 76, 50-56. [CrossRef]

21. Parveen, A.; Roy, A.S.; Rao, S. Biosynthesis and characterization of silver nanoparticles from Cassia auriculata leaf extract and in vitro evaluation of antimicrobial activity. Int. J. Appl. Biol. Pharm. Technol. 2012, 3, 222-228.

22. Dubey, S.P.; Lahtinen, M.; Särkkä, H.; Sillanpää, M. Bioprospective of Sorbus aucuparia leaf extract in development of silver and gold nanocolloids. Colloids Surf. B Biointerfaces 2010, 80, 26-33. [CrossRef] [PubMed]

23. Gavhane, A.J.; Padmanabhan, P.; Kamble, S.P.; Jangle, S.N. Synthesis of silver nanoparticles using the extracts of neem leaf and triphala and the evaluation of their antimicrobial activities. Int. J. Pharm. Biol. Sci. 2012, 3, 88-100.

24. Ahmed, S.; Ahmad, M.; Swami, B.L.; Ikram, S. A review on plants extract mediated synthesis of silver nanoparticles for antimicrobial applications: A green expertise. J. Adv. Res. 2016, 7, 17-28. [CrossRef] [PubMed]

25. Mohanta, Y.K.; Panda, S.K.; Biswas, K.; Tamang, A.; Bandyopadhyay, J.; De, D. Biogenic synthesis of silver nanoparticles from Cassia fistula (Linn.): In vitro assessment of their antioxidant, antimicrobial and cytotoxic activities. IET Nanobiotechnol. 2016, 10, 438-444. [CrossRef] [PubMed] 
26. Mariselvam, R.; Ranjitsingh, A.J.; Usha Raja Nanthini, A.; Kalirajan, K.; Padmalatha, C.; Mosae Selvakumar, P. Green synthesis of silver nanoparticles from the extract of the inflorescence of Cocos nucifera (Family: Arecaceae) for enhanced antibacterial activity. Spectrochim. Acta A Mol. Biomol. Spectrosc. 2014, 129, 537-541. [CrossRef] [PubMed]

27. Balashanmugam, P.; Caral Dinesh, R.; Manivasagan, V.; Ramesh Babu, N.G.; Kalaichelvan, P.T. Extracellular biosynthesis of silver nanoparticles using Cassia fistula extract and in vitro antimicrobial studies. J. Pharm. Res. 2014, 8, 187-191.

28. Majeed, A.; Ullah, W.; Anwar, A.W.; Shuaib, A.; Ilyas, U.; Khalid, P. Cost-effective biosynthesis of silver nanoparticles using different organs of plants and their antimicrobial applications: A review. Mater. Technol. 2016, 33, 313-320. [CrossRef]

29. El-khadragy, M.; Alolayan, E.M.; Metwally, D.M.; Serag El-Din, M.F.; Alobud, S.S.; Alsultan, N.I.; Alsaif, S.S.; Awad, M.A.; Abdel Moneim, A.E. Clinical efficacy associated with enhanced antioxidant enzyme activities of silver nanoparticles biosynthesized using Moringa oleifera leaf extract, against cutaneous leishmaniasis in a murine model of Leishmania major. Int. J. Environ. Res. Public Health 2018, 15, 1037. [CrossRef]

30. Torrisi, L.; Silipigni, L.; Restuccia, N.; Cuzzocrea, S.; Cutroneo, M.; Barreca, F.; Fazio, B.; Di Marco, G.; Guglielmino, S. Laser-generated bismuth nanoparticles for applications in imaging and radiotherapy. J. Phys. Chem. Solids 2018, 119, 62-70. [CrossRef]

31. Zhao, Y.; Zhang, Z.; Dang, H. A simple way to prepare bismuth nanoparticles. Mater. Lett. 2004, 58, 790-793. [CrossRef]

32. Pothula, K.; Tang, L.; Zha, Z.; Wang, Z. Bismuth nanoparticles: An efficient catalyst for reductive coupling of nitroarenes to azo-compounds. RSC Adv. 2015, 5, 83144-83148. [CrossRef]

33. Rieznichenko, L.S.; Gruzina, T.G.; Dypkova, S.M.; Ushkalov, V.O.; Ulberg, Z.R. Investigation of bismuth nanoparticles antimicrobial activity against high pathogen microorganism. Am. J. Bioterror. Biosecur. Biodef. 2015, 2, 1004.

34. Xia, F.; Xu, X.; Li, X.; Zhang, L.; Zhang, L.; Qiu, H.; Wang, W.; Liu, Y.; Gao, J. Preparation of bismuth nanoparticles in aqueous solution and its catalytic performance for the reduction of 4-nitrophenol. Ind. Eng. Chem. Res. 2014, 53, 10576-10582. [CrossRef]

35. Liang, Y.; Manioudakis, J.; Macairan, J.R.; Askari, M.S.; Forgione, P.; Naccache, R. Facile aqueous-phase synthesis of an ultrasmall bismuth nanocatalyst for the reduction of 4-nitrophenol. ACS Omega 2019, 4, 14955-14961. [CrossRef]

36. Ruiz-Ruiz, V.-F.; Zumeta-Dubé, I.; Díaz, D.; Arellano-Jiménez, M.J.; José-Yacamán, M. Can silver be alloyed with bismuth on nanoscale? An optical and structural approach. J. Phys. Chem. C 2017, 121, 940-949. [CrossRef]

37. Manasa, M.G.; Bhakta, A.K.; Mekhalif, Z.; Mascarenhas, R.J. Bismuth-nanoparticles decorated multi-wall-carbon-nanotubes cast-coated on carbon paste electrode; an electrochemical sensor for sensitive determination of gallic acid at neutral pH. Mater. Sci. Energy Technol. 2020, 3, 174-182.

38. Reverberi, A.P.; Varbanov, P.S.; Lauciello, S.; Salerno, M.; Fabiano, B. An eco-friendly process for zerovalent bismuth nanoparticles synthesis. J. Clean. Prod. 2018, 198, 37-45. [CrossRef]

39. Gomez, C.; Hallot, G.; Port, M. Inorganic Frameworks as Smart Nanomedicines, Chapter 10 Bismuth Metallic Nanoparticles; Grumezescu, A.N., Andrew, W., Eds.; Applied Science Publishers: London, UK, 2018; pp. 449-487.

40. Moyo, B.; Masika, P.J.; Hugo, A.; Muchenje, V. Nutritional characterization of Moringa (Moringa oleifera Lam.) leaves. Afr. J. Biotechnol. 2011, 10, 12925-12933.

41. Rodríguez-Pérez, C.; Quirantes-Piné, R.; Fernández-Gutiérrez, A.; Segura-Carretero, A. Optimization of extraction method to obtain a phenolic compounds-rich extract from Moringaoleifera Lam leaves. Ind. Crop Prod. 2015, 66, 246-254. [CrossRef]

42. Vongsak, B.; Sithisarn, P.; Gritsanapan, W. Simultaneous HPLC quantitative analysis of active compounds in leaves of Moringa oleifera Lam. J. Chromatogr. Sci. 2013, 52, 641-645. [CrossRef]

43. Gozdziewska, M.; Cichowicz, G.; Markowska, K.; Zawadac, K.; Megiel, E. Nitroxide-coated silver nanoparticles: Synthesis, surface physicochemistry and antibacterial activity. RSC Adv. 2015, 5, 58403-58415. [CrossRef]

44. Megiel, E. Surface modification using TEMPO and its derivatives. Adv. Colloid Interface Sci. 2017, 250, 158-184. [CrossRef] 
45. Kaim, A.; Szydłowska, J.; Piotrowski, P.; Megiel, E. One-pot synthesis of gold nanoparticles densely coated with nitroxide spins. Polyhedron 2012, 46, 119-123. [CrossRef]

46. Koşar, M.; Dorman, H.J.D.; Hiltunen, R. Effect of an acid treatment on the phytochemical and antioxidant characteristics of extracts from selected Lamiaceae species. Food Chem. 2005, 91, 525-533. [CrossRef]

47. Lowry, O.H.; Roserbough, N.J.; Farr, A.L.; Randall, R.J. Protein measurement with the folin phenol reagent. J. Biol. Chem. 1951, 193, 265-275.

48. Monteiro, M.C.; de la Cruz, M.; Cantizani, J.; Moreno, C.; Tormo, J.R.; Mellado, E.; De Lucas, J.R.; Asensio, F.; Valiante, V.; Brakhage, A.A.; et al. A new approach to drug discovery: High-throughput screening of microbial natural extracts against Aspergillus fumigatus using resazurin. J. Biomol. Screens 2012, 17, 542-549. [CrossRef]

49. Sarker, S.D.; Nahar, L.; Kumarasamy, Y. Microtitre plate-based antibacterial assay incorporating resazurin as an indicator of cell growth, and its application in the in vitro antibacterial screening of phytochemicals. Methods 2007, 42, 321-324. [CrossRef]

50. Hudman, D.A.; Sargentini, N.J. Resazurin-based assay for screening bacteria for radiation sensitivity. Springerplus 2013, 2, 55. [CrossRef]

(C) 2020 by the authors. Licensee MDPI, Basel, Switzerland. This article is an open access article distributed under the terms and conditions of the Creative Commons Attribution (CC BY) license (http://creativecommons.org/licenses/by/4.0/). 